\title{
LA TEORÍA DE LA TRADUCCIÓN DEL MAESTRO BALTASAR CÉSPEDES
}

Francisco Calero

$U N E D$

A esclarecer la vida y la obra del gran humanista B. Céspedes ha dedicado el doctor Andrés una importante monografia, que no ha sido aprovechada como debiera en las investigaciones posteriores; así, por ejemplo, a pesar de la abundante bibliografía sobre temas relacionados con la traducción, tanto en España como en el extranjero, creo que nadie ha aludido a la teoría de la traducción de este humanista español; este hecho no sería demasiado grave si sus ideas fueran de poca monta, pero es que resulta que su aportación es una de las más interesantes de todas las que se han escrito en la larga historia de esta materia. Yo quisiera en este trabajo poner de relieve los puntos más importantes de su pensamiento, pero antes parece conveniente hacer un resumen de su vida, dado que todavía resulta una figura no demasiado conocida en el panorama del humanismo español; en ello seguiremos el citado trabajo del doctor Andrés.

\section{Resumen de la vida de B. Céspedes}

Pocos son los datos conocidos de su vida antes de su llegada a Salamanca en el año 1583; tan sólo que nació en Granada y obtuvo el grado de Maestro en Artes en Valencia; en la Universidad de Salamanca fue presentado por una de las figuras más sobresalientes de aquella institución, fray Luis de León, ignorándose cómo llegaron a conocerse; las palabras pronunciadas por fray Luis demuestran bien a las claras el altísimo juicio que le mereció el joven humanista: «hombre eminente para la dicha regencia... y docto y 
muy apropiado para el servicio de la Universidad» (citado en Andrés, 1965, p. 21). De esta forma fue nombrado superintendente o director del Colegio de Gramática, pero sólo permaneció en este cargo dos meses, pasando en la Navidad de 1583 a ser secretario de Mateo Vázquez de Lecca, que a su vez lo era de Felipe II; no debió encontrarse muy a gusto en el nuevo puesto, pues en septiembre de 1584 lo encontramos de nuevo en Salamanca; pero seguramente el escaso sueldo percibido le impulsaria a probar fortuna en el Estudio de Medina de Rioseco; antes de su partida se había producido un acontecimiento importante, su boda con Antonia del Peso, hija del catedrático de Retórica de aquella Universidad, Francisco Sánchez de las Brozas; en Medina permaneció desde 1587 a 1592, fecha en que pasó a la Academia de Valladolid; pero tampoco aquí encontró su aposento definitivo, ya que en 1596 pasó otra vez a Salamanca, donde obtuvo la cátedra de Prima de Gramática, y en 1609 la de Griego. Su muerte tuvo lugar en 1615.

De esta ajetreada vida podemos destacar dos hechos decisivos: su amistad con fray Luis, de quien, sin duda, recibiría alguna influencia, y su matrimonio con la hija del Brocense, con quien no en todo estuvo de acuerdo.

\section{UTILIDAD DE LA TRADUCCIÓN PARA EL HUMANISTA}

Entre las tareas que Céspedes asigna al humanista está la de traducir las obras clásicas; en esta labor cita el precedente de Cicerón, que tradujo varias obras del griego:

«Es también obra del humanista no menos principal que las otras y de muy grande utilidad el traducir los authores de una lengua en otra; exerciçio que hicieron los antiguos con mucho cuidado; y tenemos de Ciceron muchas traduçiones griegas como es todo el tratado que llaman De universitate que es traducido del Thimeo de Platon y todos los Phenomemos de Arato traducidos en verso exametro y otras muchas cosas que recogio con gran curiosidad Henrico Estephano en el libro que llamo Lexicon Ciceroniarum; traduxo tambien las dos contrarias oraciones de Demosthenes y Aeschines; la qual tradducion se perdio y solo queda el proemio de ella que es el librito que se intitula $D e$ optimo genere oratorum, aunque el título es falso como se prueba por Asconio Pediano, al principio de la oracion Pro Milone, de donde se colige que no es libro de Ciçeron, aunque Fulvio Ursino en las notas quiere esforçar que sea de Ciçeron aunque no puede; este exerçiçio pues de la traduçion es de gran importançia para el que la haçe y a menester para el muchas partes que las tienen pocos de los que traduçen." (Céspedes, 1965, p. 250.) 


\section{REQUISITOS DEL TRADUCTOR}

B. Céspedes fue el primero en establecer de forma clara los tres requisitos, que desde entonces se vienen repitiendo: conocimiento de la lengua original, conocimiento de la lengua término y dominio de la materia:

"Las que todos communmente conocen son tres: La primera perfecta notiçia del lenguaje del hauthor (sic), la segunda gran conocimiento y uso de la lengua en que tradduçe y la terçera inteligencia de la materia de que se trata de author porque en cualquiera facultad ay particulares terminos della y el que no lo sabe aunque traduzca bien conforme al rigor de la letra, no sera la traduçion inteligible para los de aquella facultad; no teniendo los terminos de ella que se an de tradduçir conforme al uso de ambas lenguas con propiedad.) (Céspedes, 1965, pp. 250-251.)

Los dos primeros habian sido ya establecidos por el italiano Leonardo Bruni en 1420:

«Recte autem id (sc. interpretationem) facere nemo potest, qui non multam ac magnam habeat utriusque linguam peritam." (Citado en Kloepfer, 1967, p. 39.)

El tercero fue Luis Vives el primero en señalarlo:

«Fiunt vero falsae vel linguarum ignorantia, vel materiae, qua de agitur.» (Vives, 1536, p. 227.)

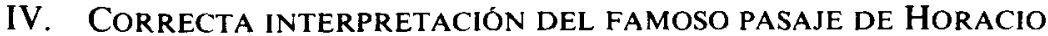 SOBRE LA TRADUCCIÓN}

Los versos 133-134 de la Epistola ad Pisones de Horacio:

"Nec verbum verbo curabis reddere fidus interpres» 
han sido interpretados al revés por muchísimos comentaristas a lo largo de la tradición clásica, y lo siguen siendo todavía en el siglo XX; a la interpretación de estos versos y de los pasajes de Cicerón referentes a la traducción dedicó V. García Yebra un trabajo en el que ofrece la interpretación correcta; la historia se remonta muy atrás: «Parece que fue San Jerónimo el primero que atribuyó a las palabras de Horacio el sentido erróneo que luego se les ha venido dando desde la Edad Media hasta nuestros días" (García Yebra, 1979-1980, p. 153). En efecto, San Jerónimo ofrece esa interpretación errónea en su Epistola ad Pammachium (Jerónimo, 1962, p. 491); en el siglo XV el alemán Niclas von Wyle mantiene la misma idea, como aparece en un texto citado por Kloepfer (cfr. Kloepfer, 1967, pp. 20-21); esta interpretación se mantuvo durante los siglos siguientes, y hasta en fechas recientes ha sido defendida por buen número de especialistas; ahora bien, ¿quién fue el primero en formular la interpretación verdadera? Posiblemente esa gloria corresponde a nuestro autor, quien en 1600 escribió estas penetrantes palabras:

\footnotetext{
"y mas creçe esta dificultad de tradduçir por estar obligado el traductor a seguir la lengua del author palabra por palabra segun, enseña Horaçio en la Poetica diciendo: Nec verbum verbo curabis reddere fidus interpres. La qual sentencia la entienden ordinariamente al reves y quieren hacer decir a Horaçio que el fiel interprete no ha de traducir palabra por palabra y en este viçio caen ordinariamente los que toman las sentençias de los authores sacadas por otros y se fian de alegaciones ajenas no leyendo ni estudiando los authores en sus libros enteros... Volviendo, pues, al verso de Horaçio, va tratando alli de la immitaçion, dice en summa que el que uviere de immitar un lugar que no le traduzca palabra por palabra como fiel interprete que esta obligado a esto.n (Céspedes, 1965, pp. 251-252.)
}

El testimonio de nuestro humanista prueba que la interpretación equivocada era la más extendida, pero también que algunos interpretaban el pasaje adecuadamente; ¿podria tratarse de fray Luis o de su suegro?; es bien posible aunque no se pueda documentar.

\section{CORRECTA INTERPRETACIÓN DE UN PASAJE DE CICERÓN SOBRE SU ACTIVIDAD TRADUCTORA}

También el conocido pasaje de Cicerón contenido en el De optimo genere oratorum ha sido con frecuencia mal interpretado: 
(sententiis iisdem et earum formam tamquam figuris, verbis ad nostram consuetudinem aptis; in quibus non verbum pro verbo necesse habui reddere, sed genus omne verborum vimque servavi.» (Cicerón, 1964, 5, 14.)

La traducción de estas líneas resulta dificil, y como prueba de ello voy a dar la realizada por dos grandes especialistas, para que se puedan comparar con la que yo propongo; esta es la de Sánchez Lasso de la Vega: "Traduzco los pensamientos; pero sus formas o, como podría también decirse, sus figuras, las traslado en una lengua ajustada a nuestra costumbre. Por eso no he traducido palabra por palabra, sino más bien el estilo general y el sentido de las palabras extranjeras) (Sánchez Lasso de la Vega, 1967, pp. 95-96); he aquí la de García Yebra: "con las mismas ideas y con sus formas a modo de figuras, pero con palabras acomodadas a nuestro uso. No me pareció necesario volver palabra por palabra, pero conservé todo su estilo y su fuerza" (García Yebra, 1979-1980, p. 140); por mi parte, propongo la siguiente: «Con las mismas ideas y con sus formas o configuraciones, pero con palabras adecuadas a nuestro uso. En ellas no tuve necesidad de volver palabra por palabra, sino que mantuve el tenor de las palabras en su conjunto y su significación.» Si se comparan estas tres traducciones, se apreciarán notables diferencias; que el lector decida cuál reproduce mejor el original, ya que no es este el momento de detenerse en ello. Lo que me interesa ahora es dejar claro que Cicerón distingue entre traducir como lo hace un traductor y como lo hace él, esto es, como orador. Que Cicerón eligiera la segunda forma no quiere decir que él pensara que el verdadero traductor tuviera que hacerlo así; por eso hay que leer con precaución las palabras de Kloepfer:

«Erster Gegner der primitiven Wörtlichkeit und vielzitiertes Vorbild des ihr gegengesetzen Typus ist Cicero; bis in das 19., teilweise sogar bis in das 20. Jahrhundert ist er für die meisten Übersetzer der 'Befreir' vom übergroßen Zwang der fremden Sprache. Der Úbersetzungstypus, den er an die Stelle der 'sklavischen Kopie' setzte, kann mit einigem Recht eine 'freie Übersetzung' genannt werden.» (Kloepfer, 1967, p. 22.)

Creo que la forma elegida por Cicerón no coincide con lo que actualmente se entiende por traducción libre, sino que más bien habria que aplicarle la formulación hecha por Quintiliano: «neque ego paraphrasin esse interpretationem tantum volo, sed circa eosdem sensus certamen atque aemulationem» (Quintiliano, 1975, X, 5, 5). Pero esto es una precisión que no es necesaria para nuestro propósito actual, ya que la interpretación del 
maestro Céspedes hace referencia sólo a la primera frase de Cicerón, y en ella acierta plenamente:

«... pruevase esto por un lugar de Ciçeron que el que uviere de immitar un lugar que no le traduzca palabra por palabra como fiel interprete, que esta en el libro dicho De optimo genere oratorum donde hablando de la tradduccion que hiço de las oraççiones de Demosthenes y Aeschines y escusandose de que no fue fiel interprete dice estas palabras: Nec converti ut interpres sed ut orator sententiis eisdem et earum formis tamquam figuris verbis ad nostram consuetudinem aptis, in quibus non verbum pro verbo necesse habui reddere; de manera que si fuera interprete necesse haberet verbum pro verbo reddere.) (Céspedes, 1965, p. 252.)

\title{
VI. Mantenimiento del estilo
}

El primero que exigió del traductor la acomodación al estilo del original fue el italiano Bruni, como se puede apreciar en estos dos significativos textos:

\begin{abstract}
"... sic in traductionibus interpres quidem optimus sese in primum scribendi auctorem tota mente et animo et voluntate convertet et quodammodo transformabit eiusque orationis figuram, statum, ingressum coloremque et linamenta cuncta exprimere meditabitur. Ex quo mirabilis quidem resultat effectus.
\end{abstract}

Rapitur enim interpres vi ipsa in genus dicendi illius, de quo transfert, nec aliter servare sensum commode peterit, nisi sese insinuet ac inflectat per illius comprehensiones et ambitus cum verborum proprietate orationisque effigie. Haec est enim optima interpretationis ratio, si figura primae orationis quam optime conservetur, et neque sensibus verba neque verbis ipsis nitor ornatusque deficiat." (Citado en Kloepfer, 1967, p. 40.)

A quien no cita Kloepfer es a Luis Vives, quien expresamente se muestra partidario de esta característica de la traducción: «Quo et gratiam orationis servaris exactius, et propius fueris interpretatus ad verbum, hoc versio erit potior ac praestabilior" (Vives, 1536, p. 231).

Otro español no citado por Kloepfer es fray Luis de León, quien de forma muy bella describe su forma de traducir: «... y pretendí que respondiese esta interpretación con el original, no solo en las sentencias y palabras, sino aun en el corriente y en el aire de ellas, imitando sus figuras y sus 
modos de hablar y maneras cuanto es posible á nuestra lengua, que á verdad responde á la hebrea en muchas cosas» (Luis de León, 1798, p. XII).

Tampoco hace mención el autor alemán del maestro Céspedes, que es tal vez quien mejor expresa este principio:

"Estas son las tres cosas que como dixe se requieren vulgarmente para traducir bien, ademas de las quales ay otra de gran importancia que por ser de muy gran dificultad veo que la guardan muy pocos; y es que se a de tradduçir de tal manera que sea el mismo estilo de la tradduçion que el de el original de dọnde se tradduçe. Llamo estilo al character y idea de oraçion, de tal manera que si el author tiene el estilo grave, aspero, suave o de otra forma la tradduçion guarde ni mas ni menos el mismo ayre y las mismas figuras, como diçe Ciçeron.» (Céspedes, 1965, p. 252.)

\section{CONCLUSIONES}

A pesar de su brevedad, creo que la teoría de la traducción del maestro Céspedes es lo más sensato, penetrante y sistemático de cuanto se ha escrito en España sobre el tema, y que iguala o supera a las grandes autoridades, como San Jerónimo, Leonardo Bruni y Lutero. Estas son sus principales aportaciones:

1. Interpreta correctamente los pasajes clásicos de Cicerón y de Horacio, que han sido frecuentemente mal entendidos, incluso en nuestros dias.

2." Fue el primero en señalar los tres requisitos esenciales del traductor: conocimiento de la lengua de origen, conocimiento de la lengua término y dominio de la materia.

3. ${ }^{*}$ Señala como obligación del traductor el mantenerse fiel a la letra del autor traducido.

4." Define con claridad qué entiende por estilo, y advierte que el traductor tiene que mantener en su traducción el mismo estilo del autor traducido.

5. Critica a los traductores que toman frases sueltas de un autor, sin tener conocimiento de la obra entera, por lo que no pueden captar 
su auténtico pensamiento. También García Yebra aprovecha la mala interpretación de Horacio para hacer una crítica parecida: «Este famoso pasaje de Horacio es ejemplo de dos cosas: de cómo un texto sin contexto puede interpretarse erróneamente, y cómo afirmaciones equivocadas se aceptan y se transmiten sin crítica» (García Yebra, 1983, p. 233.)

\section{BIBLIOGRAFÍA}

Andrés, Gregorio De, El Maestro Baltasar Céspedes y su Discurso de las Letras Humanas. Monasterio de El Escorial, Biblioteca de la Ciudad de Dios, 1965.

Bruni, LeONARDo, De interpretatione recta. Se cita por la recopilación de J. von Stackelberg: Humanistische Prosatexte aus Mittelalter und Renaissance. Tubinga. 1957.

CESPedes, Baltasar, Discurso de las Letras Humanas. Ed. de Gregorio de Andrés. Monasterio de El Escorial, Biblioteca de la Ciudad de Dios, 1965.

CicERon, De optimo genere oratorum. Ed. de A. S. Wilkins, Oxford, Clarendon Press, 1964.

Garcia Yebra, Valentín, Traducciones bíblicas y traducciones literarias. En «En torno a la traducción", Madrid, Gredos, 1983, pp. 227-236.

Garcia Yebra, Valentín, ¿Cicerón y Horacio preceptistas de la traducción? En «Cuadernos de Filologia Clásican, XVI, 1979-1980, pp. 139-154.

Horacio, Opera. Ed. H. W. Garrod. Oxford, Clarendon Press, 1932.

Jerónimo, SAN, Cartas de San Jerónimo. Ed. bilingüe de Daniel Ruiz Bueno. Madrid. BAC, 1962, V. I.

Kloepfer, Rolf, Die Theorie der literarischen Ubersetzung. Munich, Wilhelm Fink, 1967.

LUIS DE LEON, FRAY, Traducción literal y declaración del libro de los cantares de Salomón. Salamanca, Francisco de Toxar, 1798.

Quintiliano, Institutio Oratoria. Ed. de J. Cousin, París, Belles Lettres, 1975.

SÁnChEZ LASSO DE LA VEGA, La traducción de las lenguas clásicas al español como problema. En «Estudios Clásicos», XI, 50, 1967, pp. 89-140.

VIVES, JUAN LUIS, Rhetoricae, sive de recte dicendi ratione libri tres. Basilea, 1536. 